\title{
Subtrochanteric Femur Fracture in Monostotic Pagets Disease and its Management - A Case Report and Review of Literature
}

\author{
Neetin P Mahajan ${ }^{1}$, Amey Sadar ${ }^{1}$, Prasanna Kumar G S ${ }^{1}$, Pranay Kondewar ${ }^{1}$, Shubham Atal ${ }^{1}$ \\ Learning Point of the Article: \\ Intramedullary fixation with long PFN is the preferred method in treating subtrochanateric fracture in patients with pagets disease.
}

\section{Abstract}

Introduction: Paget disease of bone is a chronic progressive disease of the bone of uncertain etiology, characterized initially by an increase in bone resorption, followed by a disorganized and excessive formation of bone, leading to pain, fractures, and deformities. It can manifest as a monostotic or polyostotic disease. Pathological fracture secondary to Paget's disease requires surgical management.

Case Report: A 60-year-old male patient came with complaint of pain and swelling over the left hip for 30 days. The patient had a history of a trivial fall. Radiological investigations were suggestive of pathological subtrochanteric femur fracture with Paget's disease of the left femur. We managed with the long proximal femoral nail (PFN). Histopathological examination confirmed the diagnosis of Paget's disease. At present 1-year follow-up, the patient is having good radiological and functional outcome with no implant failure.

Conclusion: Subtrochanteric pathological femur fractures in Paget's disease are best managed with the long PFN with good outcome and fewer complications, which help in early mobilization and weight-bearing. Long PFN spans the entire pathologic femur and prevents the secondary fractures.

Keywords: Pagets disease, femur subtrochanteric fracture, long proximal femur nail.

\section{Introduction}

Paget's disease is a chronic and progressive disorder of bone characterized by focal areas of excessive osteoclastic resorption accompanied by a secondary increase in the osteoblastic activity [1]. It is characterized by focal areas of increased osteoclastic bone resorption and a coupled but disorganized increase in osteoblastic bone formation. It occurs as the result of a derangement in osteoclast formation and activity. Thus, there is an excessive and abnormal remodeling of bone, leading to bones that are extensively vascularized, weak, enlarged, and deformed. The disease is characterized by focal regions of highly exaggerated bone remodelling, with abnormalities in all phases of the remodelling process. The majority of patients with Paget's are elderly, with the age at diagnosis usually more than 50 years. Pagets disease of bone is often incidentally diagnosed, from an elevated serum alkaline phosphatase (ALP) or an incidental radiographic finding [2]. Most common symptoms of the disease include bone pain, skeletal deformities, symptoms of fractures, hearing loss, symptoms of nerve root compression, and headache. The disease may involve multiple bones (polyostotic variant) or only one bone [2]. The radiological diagnosis of Pagets is usually straightforward, but monostotic cases can cause diagnostic difficulties [3]. We present the case of monostotic femoral Pagets disease presented with subtrochanteric fracture and its management.

\section{Case Report}

A 60-year-old male patient came with complaint of pain and

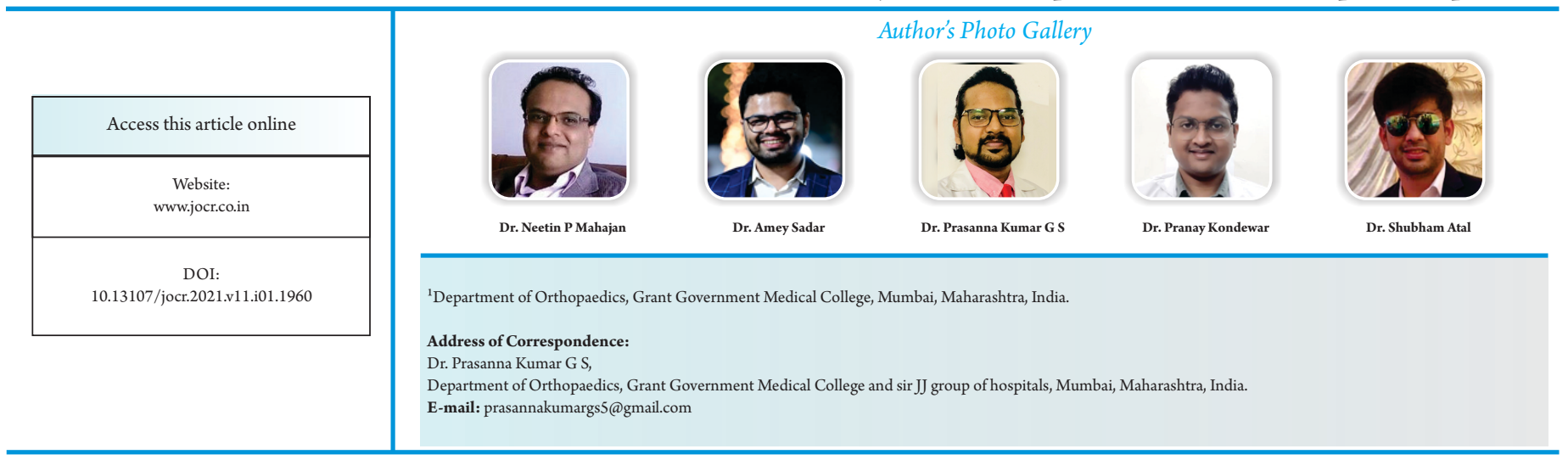

Journal of Orthopaedic Case Reports | pISSN 2250-0685 | eISSN 2321-3817 | Available on www.jocr.co.in | doi:10.13107/jocr.2021.v11.i01.1960 This is an Open Access article distributed under the terms of the Creative Commons Attribution Non-Commercial License (http://creativecommons.org/licenses/by-nc/3.0) which permits unrestricted non-commercial use, distribution, and reproduction in any medium, provided the original work is properly cited. 


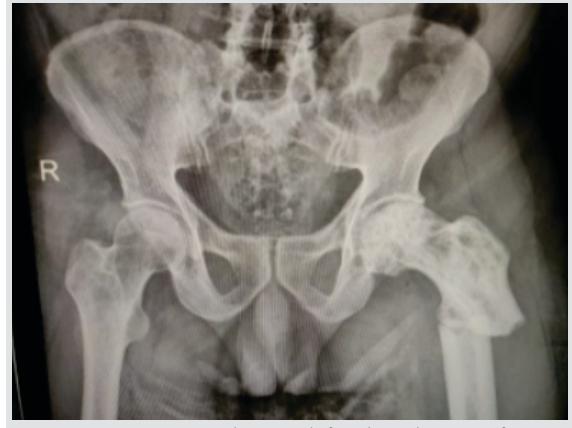

Figure 1: $\mathrm{PBH} X$-ray showing left subtrochanteric fracture with diffuse irregular cortical and trabecular bone thickening of the left femur.

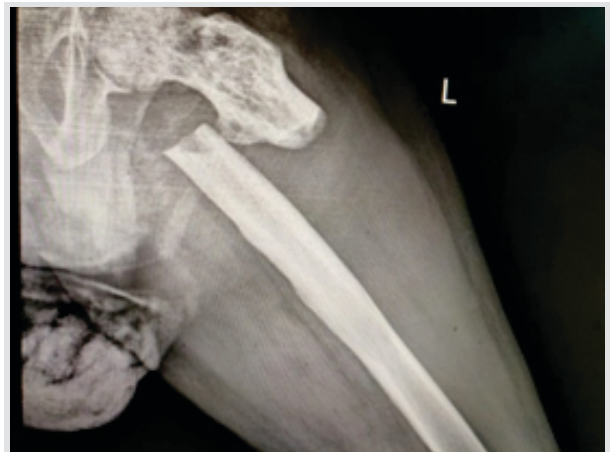

Figure 2: X-ray of the left hip with femur lateral view showing subtrochanteric fracture.

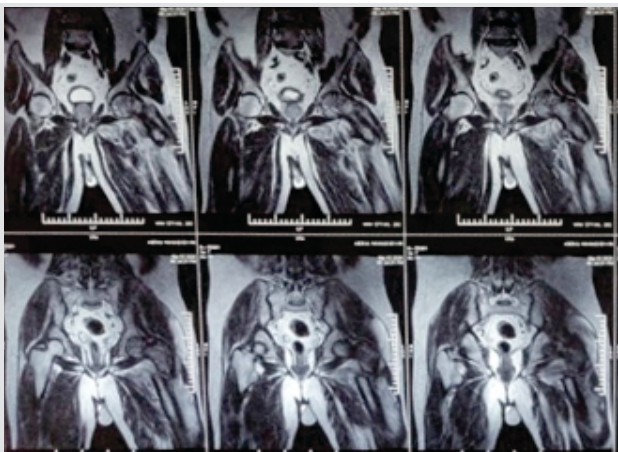

Figure 3: Magnetic resonance imaging pelvis with both hips showing pathological subtrochanteric fracture with Pagets disease. swelling over the left hip for 30 days. The patient had a history of fall in the bathroom 30 days back sustaining a trivial trauma to the left hip. The patient was weight-bearing for 1 week, after which pain was increased on walking. The patient was a known case of hypertension and diabetic on regular medications. On examination, tenderness was present at left hip region, left lower limb was externally rotated, shortened with no wound and distal neurovascular deficit.

Plain radiographs of the left hip with femur anteroposterior and lateral views revealed left subtrochanteric fracture with diffuse irregular cortical and trabecular bone thickening from the femoral head to lower third of the left femur (Fig. 1, 2). The fracture was a complete transverse through both cortices without comminution at the subtrochanteric area of the femur. Right-sided femur appeared normal. Blood investigations showed increased ALP.

Magnetic resonance imaging of pelvis with femur showed pathological fracture secondary to Paget's disease with significantly distorted bone matrix, profound hypertrophy and thickening of the bony trabeculae with significant obliteration of intervening medullary canal (Fig. 3).

As the patient was elderly, needed early mobilization and had displaced pathological subtrochanteric fracture, we planned for surgical management with intramedullary nailing. The patient was operated under spinal anaesthesia, using traction table in the supine position. Incision of around $5 \mathrm{~cm}$ was taken from the greater trochanter extending proximally. The entry point was made over the tip of greater trochanter after dissecting the soft tissues. The guide was passed in the center of the medullary canal till the distal femur, gradual progressive reaming was done using flexible reamers. Long proximal femoral nail (PFN) was inserted (size $11 \mathrm{~mm} \times 38 \mathrm{~cm}$ ) with proximal and distal locking (Fig. 4). The intraoperative sample was taken from the medullary cavity and was sent for histopathological examination. The wound was closed in layers.

The post-operative X-ray showed acceptable fracture reduction (Fig. 5, 6), the patient was mobilized off the bed from the 2nd post-operative day with partial weight-bearing. Histopathological examination confirmed the diagnosis of Paget's disease with no evidence of malignancy. Full weightbearing was started at 6 weeks. The patient became completely symptomless by 6 months. Patient was able to wight bear initially with crutches, latter he started walking independently by 6 months with no pain. At present 1-year follow-up, the patient is comfortable with no pain and difficulty in walking and having good hip and knee range of motion. The X-ray showed the union at the fracture site (Fig. 7, 8). We are still following up the patient regularly to check for implant failure and refracture.

\section{Discussion}

Paget's disease of bone (commonly known as Paget's disease or historically, osteitis deformans) is a condition involving cellular remodelling and deformity of one or more bones. The affected bones show signs of dysregulated bone remodelling at the microscopic level, specifically excessive bone breakdown and
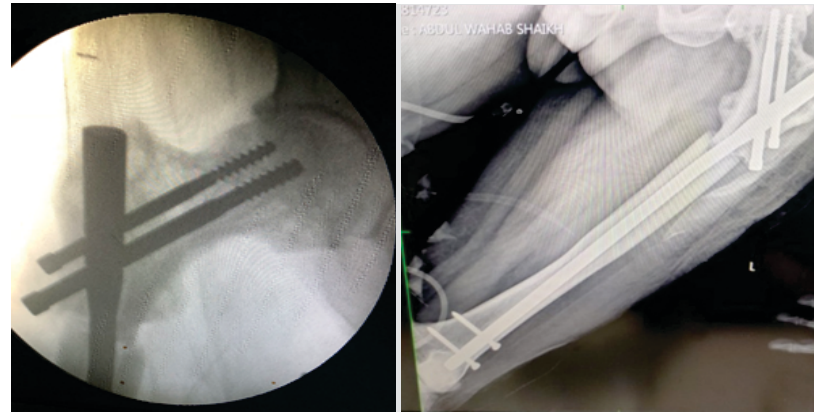

Figure 4: Intraoperative $C$ arm image Figure 5: Immediate post-operative X-ray Figure 6: Immediate post-operative $\mathrm{x}$-ray showing the proximal fixation with showing fixation with long proximal femoral lateral view. fracture reduction. nail.

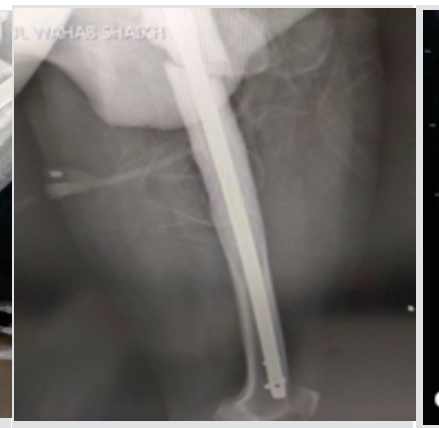

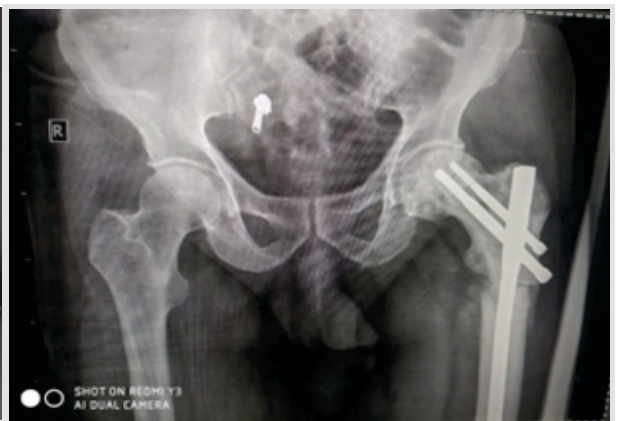

Figure 7: Follow-up X-ray at 1 year AP view. 


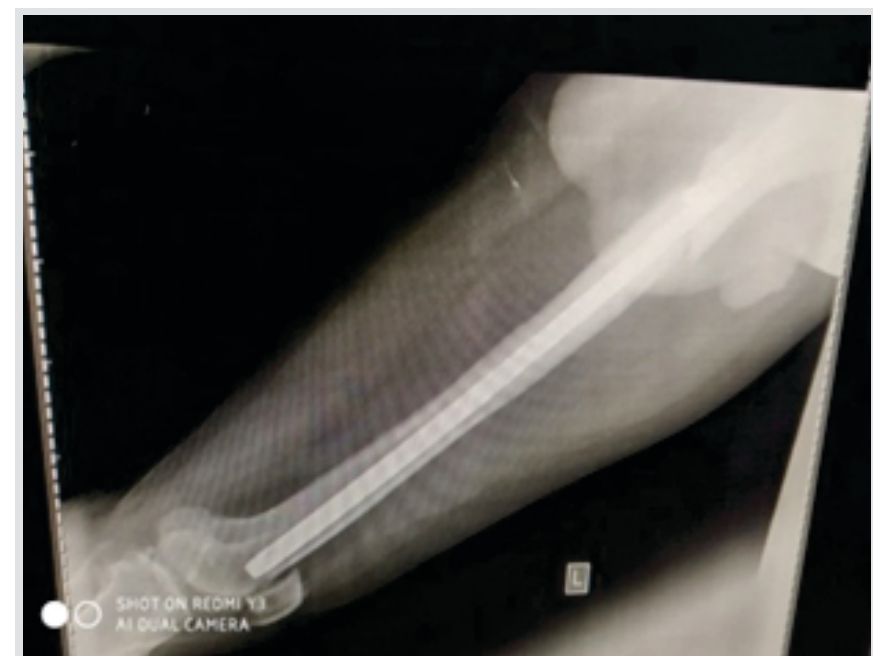

Figure 8: Follow-up X-ray at 1 year lateral view.

subsequent disorganized new bone formation [4]. These structural changes cause the bone to weaken, which may result in deformity, pain, fracture, or arthritis of associated joints. There is a high rate of bone remodelling at affected sites in the skeleton, and the bone is highly metabolically active and has a high blood flow, which can make the overlying skin feel warm to the touch [5].

The condition tends to affect an older population, which was observed in our case and unusual in individuals under 40 years of age. It can affect anything from a single bone (monostotic) to many bones (polyostotic) [6,7]. The condition is often asymmetric with, for example, only one femur involved. Paget disease of bone (PDB) is diagnosed primarily by radiological examination. Early in the course of the disease, lytic activity predominates causing focal osteolytic lesions. Subsequently, areas of sclerosis develop, leading to the characteristic appearances of mixed lytic and sclerotic areas, thickened trabeculae, bone expansion, cortical thickening, and deformity. The radiological appearances are usually characteristic, but occasionally differential diagnosis of sclerotic or lytic metastases needs to be considered. The above described radiological features were observed in our case.

Surgical options include corrective osteotomy for long bone deformity, fracture fixation, joint arthroplasty, spinal decompression, and tumor resection $[6,7]$. It is widely accepted today that Pagetic femoral fractures should be treated operatively because conservative management is associated

\section{References}

1. Walsh JP, Ward LC, Stewart GO, Will RK, Criddle RA, Prince $\mathrm{RL}$, et al. A randomized clinical trial comparing oral alendronate and intravenous pamidronate for the treatment of Paget's disease of bone. Bone 2004;34:74754.

2. Kravets I. Paget's disease of bone: Diagnosis and treatment. with difficulties in controlling the position of the fracture, particularly important for subtrochanteric fractures, where a high incidence of varus deformity, carrying an increased risk of refracture has been reported $[8,9]$. Stabilization of subtrochanteric fracture with proximal femur nail is widely accepted as treatment modality [3]. The same management was done in our case. Plating of long bones in Paget's disease causes refracture at the plate ends, it is always wise to use a long plate or intramedullary nail to span the whole bone to prevent secondary fractures. Long proximal femur nail (PFN) spans the entire femur with good stability and helps in early mobilization. When subtrochanteric femur fractures occur in patients with PDB, intramedullary nails are usually preferred for surgical stabilization $[10,11]$. Due to pathology in the bone, delayed compromised bone healing, implants may fail due to more load over the implant for an extended period of time if the fracture does not unite. Proximal femoral replacement surgery for failed operated subtrochanteric fractures in Paget's disease has been described in the literature [12]. However, in our case, gradual callus formation was observed from 3 months post-surgery. The patient became completely symptomless by 6 months. Long proximal femur nail provides immediate structural strength to the fracture. Advantage of this method is the easier operative technique, lesser operative time with fewer chances of infection.

\section{Conclusion}

Subtrochanteric pathological femur fractures in Paget's disease are best managed with the long PFN with good outcome and fewer complications, which helps in early mobilization and weight-bearing. Long PFN spans the entire pathologic femur and prevents the secondary fractures.

\section{Clinical Message}

Paget's disease must be kept in mind as one of the differential diagnosis in pathological fractures and operative management is necessary for the fixation of such fractures. Intramedullary nails help in getting better outcome with less complication in these cases. Long term follow-up is necessary to check for implant failure and refracture.

3. Winquist RA, Hansen ST, Clawson DK. Closed intramedullary nailing of femoral fractures. A report of five hundred and twenty cases. J Bone Joint Surg Am 1984;66:529-39. 
4. Paul Tuck S, Layfield R, Walker J, Mekkayil B, Francis R. Adult Paget's disease of bone: A review. Rheumatology (Oxford) 2017;56:2050-9.

5. LeBoff MS. Metabolic bone disease. In: Kelly WN, Ruddy SR, Harris, ED, Sledge C, editors. Textbook of Rhematology. 5th ed., Vol. 2. Philadelphia, PA: W.B. Saunders; 1997.

6. Merkow RL, Pellicci PM, Hely DP, Salvati EA. Total hip replacement for Paget's disease of the hip.J Bone Joint Surg Am 1984;66:752-8.

7. Kirsh G, Kligman M, Roffman M. Hydroxyapatite-coated total hip replacement in Paget's disease: 20 patients followed for 4-8 years. Acta Orthop Scand 2001;72:127-
32.

8. Dove J. Complete fractures of the femur in Paget's disease of bone.J Bone Joint Surg Br 1980;62:12-7.

9. Bradley CM, Nade $S$. Outcome after fractures of the femur in Paget's disease. Aust NZJ Surg 1992;62:39-44.

10. Cave EF. Femoral-shaft fractures treated by medullary nailing. N EnglJ Med. 1952;246:284-8.

11. Shardlow DL, Giannoudis PV, Matthews SJ, Smith RM. Stabilisation of acute femoral fractures in Paget's disease. Int Orthop 1999;23:283-5.

12. Acheampong DO, Forsh DA. Proximal femoral replacement for subtrochanteric femur nonunion in Paget's disease of the bone: A case study. Res Rev Orthop 2016;1:18-23.

Conflict of Interest: Nil

Source of Support: Nil

Consent: The authors confirm that informed consent was obtained from the patient for publication of this case report

\section{How to Cite this Article}

Mahajan NP, Sadar A, Prasanna GS, Kondewar P, Atal S. Subtrochanteric Femur Fracture in Monostotic Pagets Disease and its Management - A Case Report and Review of Literature. Journal of Orthopaedic Case Reports 2021 January; 11(1): 51-54. 